\title{
Four-Electron Reduction of Oxygen Electrocatalyzed by a Mixture of Porphyrin Complexes onto Glassy Carbon Electrode
}

\author{
Leyla Gidi ${ }^{1}$, Camila Canales ${ }^{1}$, María J. Aguirre ${ }^{2}$, Francisco Armijo ${ }^{1}$, and Galo Ramírez, ${ }^{1}$ * \\ ${ }^{1}$ Facultad de Química, Departamento de Química Inorgánica, Pontificia Universidad Católica de \\ Chile, Av. Vicuña Mackenna 4860, Casilla 306, Correo 22, Santiago, Chile. \\ ${ }^{2}$ Facultad de Química y Biología, Departamento de Química de los Materiales, Universidad de \\ Santiago de Chile USACH. Av. L.B. O’Higgins 3363, Santiago, Chile. \\ *E-mail: gramirezj@uc.cl
}

doi: $10.20964 / 2018.02 .07$

Received: 24 September 2017 / Accepted: 18 November 2017 / Published: 28 December 2017

\begin{abstract}
In this work a new composite electrode for the electrocatalytic reduction of oxygen (ORR) is presented. For this purpose, glassy carbon electrodes (GC) were modified with $\mathrm{Co}^{\mathrm{II}}$ and $\mathrm{Fe}^{\mathrm{III}}$ octaethylporphyrins. The system that presents the highest electrocatalytic activity towards ORR is GC modified with a mixture of both octaethylporphyrins in 1:1 volume proportion (GC Co-Fe 1:1) over the GC electrodes modified with $\mathrm{Co}^{\mathrm{II}}$ and $\mathrm{Fe}^{\mathrm{III}}$ octaethylporphyrins separately. This modified electrode can reduce $\mathrm{O}_{2}$ through two reduction processes (four electrons each), by the generation of $\mathrm{H}_{2} \mathrm{O}$ as final product, in two active sites of different chemical nature. All the electrodic systems were morphologically characterized by atomic-force microscopy (AFM) and electrically characterized by electrochemical impedance spectroscopy (EIS). It was found that the electroactive system (GC Co-Fe 1:1) presents high differences on its surface and performs the lowest charge transfer resistance (Rct) in comparison to the rest of the modified systems and GC itself.
\end{abstract}

Keywords: Dioxygen reduction, Modified electrode, porphyrin complex mixtures, Electrocatalysis, Synergic effect

\section{$\underline{\text { FULL TEXT }}$}

(C) 2018 The Authors. Published by ESG (www.electrochemsci.org). This article is an open access article distributed under the terms and conditions of the Creative Commons Attribution license (http://creativecommons.org/licenses/by/4.0/). 